\title{
Comparative Assessment of the Accuracy of the Elevation differences obtained from different Geomatics Techniques and Instruments
}

\author{
Audu, H.A.P. ${ }^{1, *}$ and Tijjani, M.Y. ${ }^{2}$ \\ ${ }^{1}$ Department of Civil Engineering, University of Benin, Benin City, Nigeria \\ ${ }^{2}$ Department of Geomatics, University of Benin, Benin City, Nigeria \\ Corresponding Author:*henry.audu@uniben.edu
}

\begin{abstract}
This study carried out the comparative evaluation of the accuracy of elevation differences determined from two Geomatics instruments and techniques in part of University of Benin, Ugbowo Campus. Reconnaissance survey was carried out and the two Geomatics instruments (Total station instrument and the Automatic level instrument) used for this study were tested and found to be in good working conditions. In line with the survey regulation, the position of the control stations (UB GPS101and UB GPS102) where the survey commenced were checked for disturbance and the obtained angular and linear measurements proved that the control stations were in situ. The perimeter traversing, using the total station instrument, with closed traverse technique and the perimeter levelling using the trigonometric levelling method and the level instrument with flying level both commenced from the GPS control stations and terminated at the same control stations. The known coordinates of UB GPS102, when compared with those determined with the total station instrument, have some millimetres differences. The difference in the elevation of the GPS control station and the elevation determined for the same control station with the total station instrument was in millimetre. These values were within the specified and acceptable accuracy limits. The accuracy of the tertiary traverse survey, which has satisfied the allowable accuracy limits for tertiary traverse survey, was 1: 41,428.043. The allowable accuracy for third order levelling for the study area was 26mm. Their computed accuracies using the total station and level instruments were $21 \mathrm{~mm}$ and $13 \mathrm{~mm}$ respectively. Although the elevations determined from the two Geomatics instruments met the standard accuracy limits for tertiary levelling, the accuracy of the elevations obtained with the level instrument is higher than those obtained with the total station instrument. These results are in conformity with the findings of some researchers on the related subject matter.
\end{abstract}

Keywords: Elevations, Accuracy, Differential levelling, Trigonometrical levelling, Total Station and Level instrument

\subsection{Introduction}

Elevations are vital data for mapping, engineering design and construction. They are used to design highways, railroads, canals, sewers, water supply systems and other facilities having grade lines that best conform to existing topography; layout construction projects according to planned elevations; calculate volumes of earth work and other materials; investigate drainage characteristics of an area; develop maps showing general ground configuration as well as study earth subsidence and crustal motion (Wolf and Ghilani, 2012).

The Geomatics instruments/equipment commonly used nowadays such as Electronic Total Station(ETS), Robotic Total Station(RTS), Digital Levelling Equipment, Electronic Field Books, the Global Navigation Satellite System(GNSS), Terrestrial Laser Scanner(TLS), Unmanned Aerial Vehicle (UAV), Analytical Plotters and Digital Mapping Equipment for Geomatics services are better, faster, more accurate, easier to use and are of higher quality and accuracy when compared to the conventional surveying instrument/equipment used in the ancient times. Besides, it will be impossible for the Geomatics professionals to do the quality works and time expected of them by the modern and enlightened society without the modern and digital Geomatics equipment (McCormac, 2004). Geomatics services are required before, during and after the construction of most engineering 
infrastructure located on the earth's surface, and plays immense role in the environmental development and management of developing and developed nations of the World.

The knowledge of the accuracy of the Geomatics instruments/equipment and techniques for certain Geomatics applications plays significant roles in achieving the results that will meet the specifications of the given Geomatics projects. If instruments and methods which yield accuracy far above the needed standard are used for a Geomatics project, it will result in unnecessary expenditure and cost. On the other hand, if the instruments and techniques used for a particular Geomatics application yield accuracy far below the required standard and specifications, the effect is more costly. Therefore, any surveying task comprises not only the derivation of relative positions of points and objects but also an estimation of the accuracy of the results (Boehler and Marbs, 2010). Precise and accurate measurement of points and objects on the earth's surface is one of the main objectives of the Geomatics Engineers.

Several studies in most developed nations of the world have compared the accuracies of elevation differences obtained by trigonometric levelling using modern total station instruments to those achieved by differential levelling. This study is therefore an empirical research that is focused on expanding or confirming the existing knowledge on the above subject matter.

The objectives of the study are to: examine two Geomatics instruments, viz: total station instrument and the automatic level instrument, acquire levelling data with the instruments for the study area, process the levelling data, determine the accuracy of the elevations obtained from the two instruments, compare and analyse the results of the accuracy with the standard accuracy limits for levelling operations.

\subsection{Geomatics Instruments and Techniques for the Determination of Elevations}

The elevation of a particular point or geographic location is the vertical distance above or below a reference level surface (most commonly a reference geoid, a mathematical model of the earth's sea level as an equipotential gravitational surface). Elevation of points on the earth's surface, determined through levelling, is of prime importance to all professionals in the Construction industry, especially the engineers in the design of all classes of works, during construction operations and in many GIS related tasks. (Arora and Badjatia, 2011; McCormac, 2004).

Levelling is the general term applied to any of the various processes by which elevations of points or differences in elevations are determined. It is a branch of surveying, the object of which is to determine the elevation of a given point with respect to the given or assumed datum; and to establish a point at a given elevation with respect to the given or assumed datum. Common levelling instruments include the spirit level, the dumpy level, the digital level and the laser level (Schofield, 2001).

Differences in elevations have traditionally been determined by differential (spirit) levelling and barometric levelling, and indirectly by trigonometrical levelling. Differential levelling is the process of determining the difference in elevation between two points. With trigonometrical levelling, distances and angles are measured and elevation difference is calculated by trigonometry. The differences in elevation between two points can be determined by measuring the inclined or horizontal distance between them and the zenith angle or the altitude angle to one point from the other. It can be used to determine elevation of inaccessible points such as mountain peaks, church steeples and offshore platforms (Wolf and Ghilani, 2012; McCormac, 2004). With barometric levelling, elevations are determined by measuring changes in air pressure. The differential levelling and trigonometrical levelling are the most commonly used methods for determination of elevations of ground points and differences in elevations relative to a reference datum (Schofield, 2001).

A newer method involves measuring vertical distances electronically. The application of a tape to a vertical line between points is used to measure depths of mine shafts, determine floor elevations in surveys and layout, multi-story buildings, pipelines etc. A graduated pole or rod can replace the tape when laying water or sewer lines. In certain situation, especially on construction projects, reflectorless electronic distance measurement or electronic total station devices are replacing the tape for measuring vertical distances in construction sites (Wolf and Ghilani, 2012).

A total station is an instrument that can measure both horizontal and vertical angles electronically and perform limited computational tasks such as reduction of slope distance to horizontal distance, 
computation of coordinates given the bearing and distance of a line etc. With a total station instrument, horizontal and vertical angles and slope distances are automatically read and with these measurements, the microprocessor instantaneously computes horizontal and vertical components of slope distances as well as elevations and coordinates of sighted points (Arora and Badjatia, 2011; McCormac, 2004). The numerous significant advantages of total stations have made them predominant instruments used in Geomatics practice in modern days. They are used for all types of surveys including topographic, hydrographic, cadastral, and construction surveys.

An automatic level is an optical instrument used to establish or check points on the same horizontal plane. It is used in surveying and building with a vertical staff to measure height difference and to transfer, measure and set heights.

\subsection{Accuracy of levelling operations}

The terms accuracy and precision are constantly used in Geomatics Engineering, yet their correct meaning are different. Accuracy refers to the degree of perfection obtained in measurements. It denotes how close a given measurement is to the true value of the quantity. It is the degree of conformity or closeness to the true value. Precision is the degree of refinement with which a given quantity is measured. In other words, it is the degree of closeness or conformity of repeated measurements of the same quantity to each other. Better precision does not necessarily mean better accuracy. The objective of the Geomatics Engineers is to make measurements that are both precise and accurate (McCormac, 2004; Mikhail and Gracie, 1981).

For normal engineering work and site surveys, the allowable misclosure for any levelling sequence is often given. According to Ehiorobo (2002), the elevation difference accuracy, B, is computed for a minimally constrained, correctly weighted, least squares adjustment by:

$$
\mathrm{B}=\mathrm{M}_{\mathrm{b}} \sqrt{D}
$$

Where,

$\mathrm{B}=$ elevation difference accuracy

$\mathrm{D}=$ approximate horizontal distance in kilometres between the control points position traced along existing level routes.

$\mathrm{M}_{\mathrm{b}}=$ the propagated standard deviation of elevation difference in millimetre between survey control obtained from the least square adjustment.

Muskett (2005) opined that within a limited area, the allowable closing error is taken to be proportional to the square root of the instrument stations; for long levelling runs, it is proportional to the square root of the distance levelled. Uren and Price (1994) reported that the difference between the calculated and known values of the reduced level (R.L) of the temporal bench mark/bench mark (TBM/BM) which is known as the misclosure, gives an indication of the accuracy of the levelling operation. If the obtained misclosure is outside the allowable misclosure (AM), then the levelling must be repeated. If the misclosure is within the allowable value, then it is distributed throughout the levels as corrections. In other words, when the actual misclosure (calculated from field survey) and allowable misclosure are compared and it is found that the actual value is greater than the allowable value, the levelling operation should be repeated. The permissible accuracy or allowable misclosure determines the specified limit of the accuracy of any levelling operation.

In Nigeria, the Surveyors Council of Nigeria (SURCON) is responsible for providing the allowable misclosure (permissible accuracy). For this study, the standard conditions used for the accuracy of the levelling are stipulated in the specifications for Geodetic Surveys in Nigeria (SURCON 2003a) and Specifications for Large Scale, Cadastral and Engineering Surveys in Nigeria (SURCON 2003b). In accordance with SURCON (2003a), the specified limit for the second order levelling operations, the elevation difference between two Bench marks, is calculated and determined using the following mathematical expressions:

$$
\text { Allowable (Permissible) Accuracy }=8.4 \mathrm{~mm} \sqrt{k}
$$


Where,

$\mathrm{K}=$ the total distance of the levelling operation in kilometre

Furthermore, the specified limit for third order levelling operations is calculated and determined with the following mathematical relationship (SURCON, 2003b):

Permissible Accuracy $=24 \mathrm{~mm} \sqrt{k}$

Where,

$\mathrm{K}=$ the total distance of the levelling operation in kilometre

\subsection{Materials and Methods}

\subsection{The study Area}

The study area is located within University of Benin, Ugbowo Campus, in Egor Local Government Area, Benin City, Edo State. It lies within geographical extent of rectangular coordinates 265 $005.513 \mathrm{mN}-265175.830 \mathrm{mN}$ and $353623.314 \mathrm{mE}-353716.045 \mathrm{mE}$ and geographical location of $265005.513 \mathrm{mN}, 353623.314 \mathrm{mE}$ and $265175.830 \mathrm{mN}, 353716.045 \mathrm{mE}$ in National origin, Edo State. The Satellite imagery which shows the study area is presented in Figure 1.

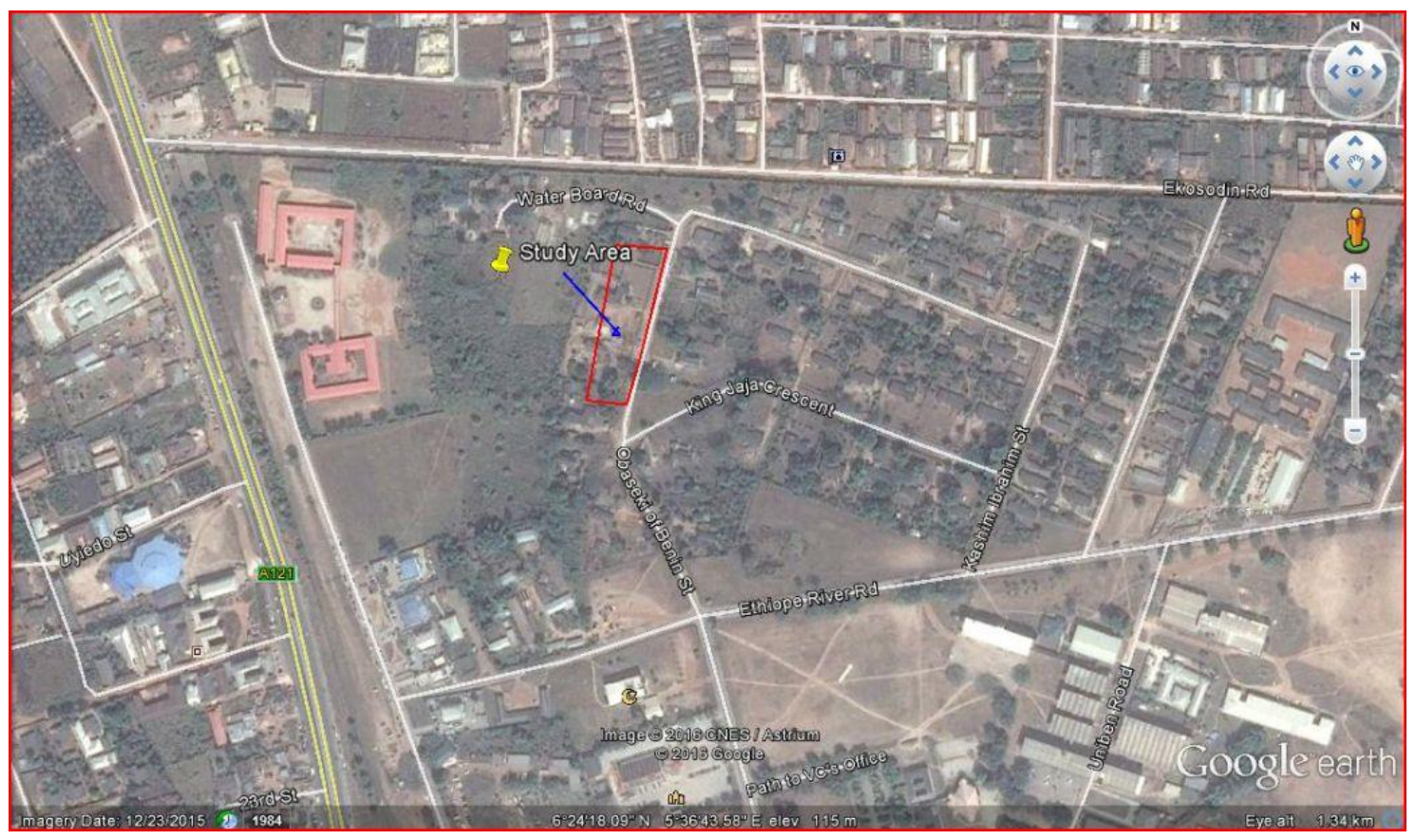

Figure 1: The Satellite imagery showing the location of the study area in University of Benin, Ugbowo Campus (Source: Google Earth)

\subsection{Data acquisition, processing and presentation}

\subsubsection{Data acquisition}

During the reconnaissance survey, the survey crew visited the project site in order to be acquainted with the site conditions, the volume of survey work especially with the line clearing, existing features as well as have the general overview of the topography of the area. This information was of immense help in the project planning and pre-analysis of the entire study. Furthermore, pre-analysis of the entire study, which was carried out, assisted in determining the project components and methodology that would achieve the aim and objectives of the study, satisfy the required accuracy standard and specifications for large scale, Cadastral and Engineering Surveying in Nigeria as well as the Survey Rules and Regulations. 
The two Geomatics instruments that were used for this study were the total station instrument (TSI) and the automatic level instrument (ALI). The total station instrument was tested and found to be in good working condition, while the results of two-peg test which was carried out on the automatic level instrument in order to prevent the compensator error also show that the instrument was in good working condition. These tests were performed in order to ensure that the instruments were in good working condition, reliable and that the geometry of the instruments was not altered or was within tolerance. The tests also help to prevent instrumental errors. Since these Geomatics instruments were found to be in good working conditions, they were therefore used for this study.

In line with the survey regulation, the position of the control points (UB GPS101and UB GPS102) where the survey commenced, were checked for disturbance. Angular and linear measurements were carried out and the obtained results proved that the control stations were in situ. The perimeter traversing of the boundary survey of the area commenced from the existing GPS Control Stations (UB GPS101 and UB GPS 102) located along river Ethiope road and Faculty of Engineering, University of Benin using Total Station instrument. The temporal adjustment of the instrument was carried out. The instrument was used to measure the slope distances, horizontal angles, vertical angles and coordinates of the second point in the traverse line and all the parameters were stored in the instrument's memory. The instrument was moved to the second point and the procedure used at the first point was repeated except that the back azimuth to the first point and the coordinates of the second point were recalled from the instrument's memory after which the next point was sighted. This procedure was continued till the Geomatics crew returned to the initial point (UB GPS102) whose coordinates are known. The coordinates of this ending point (UB GPS102) was compared with those determined with the total station instrument and were found to be of some millimetres differences (errors of closure). The errors of closure were within the acceptable limits. Ehigiator-Irughe and Okonofua (2016) evaluated the positional accuracy of the three UNIBEN Geodetic controls (UB GPS100, UB GPS101, UB GPS102) and reported that the accuracy standard for these Geodetic controls met the National Geodetic Reference System.

The determination of the elevations and the elevation differences using total station instrument was carried out using trigonometric levelling method. In order to obtain the elevation of the points during the traversing with the total station instrument, the height of the instrument and the height of the reflector were entered into the instrument and the microprocessor of the instrument computed the vertical components of the slope distance, correction for the earth's curvature and atmospheric refraction and then determine the elevation of the next point. This procedure continued until the last point was reached. The difference in its elevation and the one determined with the instrument was in millimetre, which was within the specified accuracy limits (presented in Table 1). Therefore, the adjustment of all the intermediate points was done and the final elevations of the points were determined.

The perimeter levelling operation was carried out in a loop using the differential (spirit) levelling method and the automatic level instrument. The levelling operation also started from the GPS control station (UB GPS102) whose elevation was known and closed back on the same GPS Station (UB GPS102) with flying levels and booking was done with the levelling sheets. The field procedure involved double run with forward and backward measurement for every section.

The effect of curvature in this measurement is to cause the staff readings to be too high, while the effect of atmospheric refraction on the line of sight is to bend it towards the earth surface thereby causing the staff readings to be too low. The combined curvature and refraction correction can be computed from the formula (Uren and Price, 1994):

$$
\mathrm{C}+\mathrm{r}=0.0673 \mathrm{D}^{2}
$$

Where,

$$
\begin{array}{ll}
\mathrm{C} & =\text { curvature in metres } \\
\mathrm{r} & =\text { refraction } \\
\mathrm{D} & =\text { sighting distance }
\end{array}
$$


The effect of curvature and refraction is negligible when undertaking levelling of third order of accuracy whose sighting distances are less than $120 \mathrm{~m}$. Furthermore, their effect will cancel out if the sight lengths are equal. The effect of curvature and refraction are negligible in this study since the sight lengths were less than $120 \mathrm{~m}$.

\subsubsection{Data processing and Accuracy Analysis}

The traverse survey was computed with the in-built Trimble software of the total station instrument to obtain the coordinates of the traverse points. The errors of closure were within the acceptable limits, and therefore proportional adjustment was made to the intermediate traverse points to produce their final planimetric coordinates (presented in Table 2).

The accuracy of the traverse survey (Linear misclosure) for the specified limit of the third order traversing operations in this study, was calculated and determined using the following mathematical expressions (SURCON, 2003a):

$$
\text { Linear Accuracy }(\mathrm{LA})=\frac{\sqrt{(\Delta \mathrm{N})^{2}+(\Delta \mathrm{E})^{2}}}{\text { total distance }}
$$

Where,

$\Delta \mathrm{N}=$ Difference in the Northing Coordinates of the known and obtained values for the GPS station

$$
\text { (UBGPS 102) }
$$

$\Delta \mathrm{E}=$ Difference in the Easting Coordinates of the known and obtained values for the GPS station

\section{(UBGPS 102)}

$\Delta \mathrm{N}=-0.004, \Delta \mathrm{E}=-0.028$; Total distance for the perimeter Survey $=1,171.762 \mathrm{~m}$

LA $=1:$ 41,428.043 (Obtained)

The accuracy of the traverse survey was 1: 41,428.043 and it satisfied the allowable accuracy for the tertiary boundary traverse survey in Nigeria. The obtained accuracy also satisfied the minimum accuracy standard of tertiary traversing of Geodetic control survey whose class I is 1:10,000 and class II is 1:5,000 (FGDC, 1998). The area of the property was computed from the coordinates of the boundary using AutoCAD software and cross checked with cross coordinates (analytical) method of area computation.

The computed and permissible (allowable) accuracy and standard for third order levelling for this study is shown in Table 1.

Table 1: Computed and permissive (allowable) standard accuracy for tertiary levelling with TSI and ALI

\begin{tabular}{llll}
\hline S/N & ITEM & Computed Accuracy & Permissible Accuracy \\
\hline 1 & $\begin{array}{l}\text { Levelling operation for the } \\
\text { determination of elevations and } \\
\text { elevation differences }\end{array}$ & $\begin{array}{l}\text { The accuracy in the levelling } \\
\text { operation (fh) from: } \\
\text { the TSI }=\text { is } 21 \mathrm{~mm}\end{array}$ & For 3rd order levelling: \\
& the ALI = is $13 \mathrm{~mm}$ & $\begin{array}{l}\text { Permissible Misclosure (P.M.) }=24 \mathrm{~mm} \sqrt{k} \\
\text { where, } \\
\end{array}$ & $\begin{array}{l}\mathrm{K}=\text { the total distance of the levelling } \\
\text { operation in kilometre }\end{array}$ \\
& $\begin{array}{l}\text { P.M. }=24 \mathrm{~mm} \sqrt{1.172} \quad=25.982 \mathrm{~mm}= \\
26 \mathrm{~mm}\end{array}$ \\
& $\mathrm{~K}=1.172 \mathrm{~km}$ & \\
\end{tabular}


The height of Instrument method was used for the reduction of the levelling field sheets, while the levels were adjusted by the Bowditch method and the corrections applied to get the final reduced levels (elevations) (shown in Table 2).

\subsubsection{Data presentation}

The processed data were modelled using CAD (AutoCAD) software and the traverse survey plan was produced at scale 1:2000.

\subsection{Results and Discussion}

The summary of the rectangular coordinates and elevations determined with the total station instrument (TSI) for the study area is presented in Table 2. These rectangular coordinates played significant roles in the location and geo-spatially positioning of the boundary lines of the study area. The accuracy of the tertiary traverse survey with the total station instrument, which produces the rectangular coordinates in Table 2, was 1: 41,428.043. This accuracy has satisfied the allowable accuracy limits for tertiary traverse survey in Nigeria. The elevations in Table 2, which were determined with the total station instrument met the standard accuracy limits for third order levelling.

Table 2: Rectangular Coordinates and Elevations determined with Total Station instrument for the study area.

\begin{tabular}{cccc}
\hline Station & $\mathbf{N}(\mathbf{m})$ & $\mathbf{E}(\mathbf{m})$ & $\mathbf{H}(\mathbf{m})$ \\
\hline UB 100AC & 266175.830 & 353652.079 & 128.899 \\
UB 101AC & 266173.841 & 353716.045 & 128.842 \\
UB 102AC & 266054.145 & 353684.744 & 128.793 \\
UB 103AC & 266005.513 & 353671.448 & 129.044 \\
UB 104AC & 266016.656 & 353623.314 & 128.875 \\
UB 105AC & 266093.659 & 353634.323 & 128.829 \\
\hline
\end{tabular}

Table 3 shows the summary of elevations of points obtained with Automatic Levelling Instrument (ALI) through the differential levelling. These elevations also satisfied the standard accuracy limits for tertiary levelling. The comparative analysis of the accuracy of the elevations from TSI and ALI is presented in Table 4.The allowable (permissible) accuracy (misclosure) for third order levelling for the study area was $26 \mathrm{~mm}$. The computed accuracy for the third order levelling operation in the study area with the Total Station instrument was $21 \mathrm{~mm}$ while with Automatic Level instrument, the computed accuracy was $13 \mathrm{~mm}$ (shown it Table 4). Although the results(empirical values) of the accuracy obtained from the two Geomatics instruments fall within the permissible accuracy for third order levelling, the accuracy of the results(elevations) obtained with automatic level instrument is higher than the accuracy of the results(elevations) obtained with total station instrument. These results have confirmed the research findings of Ghilani and Wolf (2012) and McCormac (2004) on the related subject matter.

According to McCormac (2004), the results of total station instruments which are commonly used nowadays for determining various elevations are quite good, but not as accurate as those obtained with level instruments. Ghilani and Wolf (2012) opined that trigonometric levelling accuracies have always been limited by instrumental errors and the effects of refraction. Even with these problems, elevations derived from a total station survey are of sufficient accuracy for many applications such as topographic mapping and other lower-order work. For route surveys, elevations are determined with total station /Stadia tacheometry instrument in rugged and hilly terrain, while in flat terrains elevations are determined with a level instrument. 
Table 3: Summary of Elevations of points obtained with Automatic Levelling Instrument

\begin{tabular}{cc}
\hline Station & Elevations obtained from Automatic Level Instrument $(\mathbf{m})$ \\
\hline 1 & 128.857 \\
2 & 128.848 \\
3 & 128.915 \\
4 & 128.905 \\
5 & 128.745 \\
6 & 128.752 \\
7 & 128.840 \\
8 & 128.824 \\
9 & 128.859 \\
10 & 128.868 \\
11 & 129.055 \\
12 & 128.865 \\
13 & 128.824 \\
14 & 128.811 \\
15 & 128.928 \\
16 & 128.835 \\
17 & 128.942 \\
UB $103 \mathrm{AC}$ & 129.080 \\
UB $104 \mathrm{AC}$ & 128.904 \\
\hline
\end{tabular}

Table 4: Comparative analysis of the Accuracy of the Elevations obtained from the levelling operation using TSI and ALI

\begin{tabular}{cccc}
\hline Station & $\begin{array}{c}\text { Total Station Instrument } \\
\text { Elevation }(\mathbf{m})\end{array}$ & $\begin{array}{c}\text { Automatic Level } \\
\text { Instrument } \\
\text { Elevation }(\mathbf{m})\end{array}$ & $\begin{array}{c}\text { Given } \\
\text { Elevation(m) of } \\
\text { UB GPS102 }\end{array}$ \\
\hline Start from UB GPS102 & 128.846 & 128.846 & 128.846 \\
$\begin{array}{c}\text { Close back on UB } \\
\text { GPS102 } \\
\text { Difference }\end{array}$ & 128.825 & 128.859 & \\
\hline
\end{tabular}

The differences in elevations obtained from the study area using the two Geomatics instruments are shown in Table 5. In this table, the heights of some points in the study area have shown some millimetres differences. These differences in the elevations range from $20-62 \mathrm{~mm}$. The Survey plan showing the location of the study area in University of Benin is presented in Figure 2.

Table 5: Differences in elevation obtained from the Study Area using two Geomatics instruments

\begin{tabular}{cccc}
\hline Station & Total Station Instrument $(\mathbf{m})$ & Automatic Level Instrument $(\mathbf{m})$ & Difference $(\mathbf{m m})$ \\
\hline 1 & 128.826 & 128.857 & 31 \\
2 & 128.786 & 128.848 & 62 \\
3 & 128.881 & 128.915 & 34 \\
4 & 128.877 & 128.905 & 31 \\
5 & 128.697 & 128.745 & 48 \\
6 & 128.710 & 128.752 & 42 \\
7 & 128.809 & 128.840 & 31 \\
8 & 128.766 & 128.824 & 58 \\
9 & 128.839 & 128.859 & 20 \\
10 & 128.836 & 128.868 & 32 \\
11 & 129.021 & 129.055 & 34 \\
12 & 128.816 & 128.865 & 49 \\
13 & 128.772 & 128.824 & 52 \\
14 & 128.784 & 128.811 & 27 \\
15 & 128.880 & 128.928 & 48 \\
16 & 128.810 & 128.835 & 25 \\
17 & 128.922 & 128.942 & 24 \\
UB103AC & 129.044 & 129.080 & 36 \\
UB104AC & 128.875 & 128.904 & 29 \\
\hline
\end{tabular}




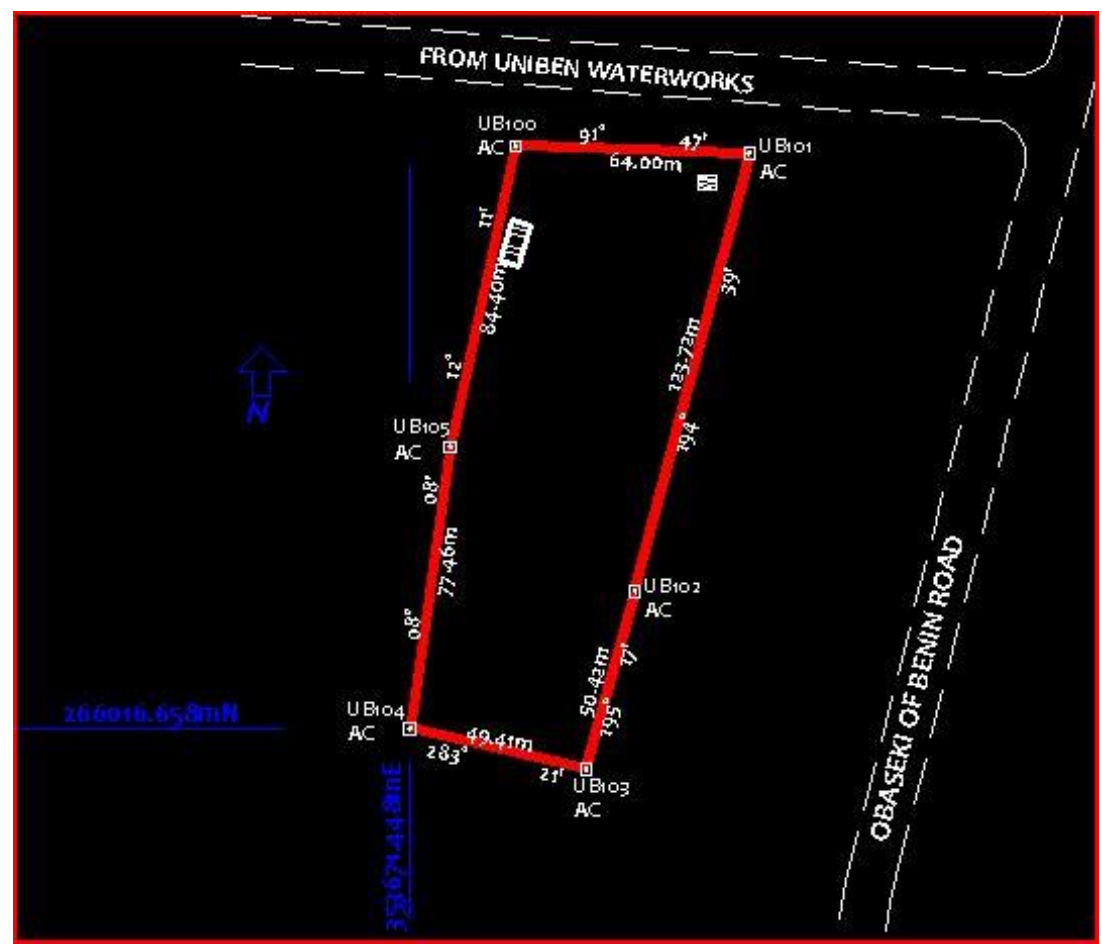

Figure 2: Survey plan showing the location of the study area in University of Benin, Ugbowo Campus

\subsection{Conclusion}

This study has carried out an empirical research that seeks to verify the existing knowledge about the accuracy of some Geomatics instruments and their applications in providing Geomatics services to the socio-economic development of the society. The results of the study have shown that the accuracy obtained from the two Geomatics instruments fall within the permissible accuracy for third order levelling. However, the accuracy of the results obtained with Automatic Level instrument is higher than the accuracy of the results (elevations) obtained with Total Station instrument. Furthermore, the results of this study confirm the research findings of some researchers on the related subject matter.

\section{References}

Arora, M.K. and Badjatia, R.C. (2011), "An introduction to Geomatics Engineering", $1^{\text {st }}$ Edition, published by Nem Chand and Bros.,Roorkee, India

Boehler, W. and Marbs, A. (2010), "Investigating Laser Scanner Accuracy”, URL: http://scanning.thmainz.de/scannertest/results300305.pdf

Ehigiator-Irughe, R. and Konofua, S. (2016), "Accuracy Standard of UNIBEN First order GNSS Geodetic Controls", Journal of the Nigerian Institution of Production Engineers, Benin City, Vol. 20, pp 145-149.

Ehiorobo, J.O. (2002), "GIS in Infrastructural Development and Management", Technical Transaction, Journal of the Nigerian Institution of Production Engineers, Benin City, Vol.7, No 3, pp 136-146.

Federal Geographic Data Committee (FGDC), (1998), "Geospatial Positioning Standards", Standards for Geodetic Networks of the Geodetic Control Subcommittee of FGDC, Virginia, USA

Ghilani, C.D. and Wolf, P.R. (2012), "Elementary Surveying: An Introduction to Geomatics", $13^{\text {th }}$ edition, published by Pearson Education Inc., New Jersey, 983pp 
McCormac, J. (2004), "Surveying", $5^{\text {th }}$ Edition, Published by John Wiley and son Inc. Heboken,USA, $458 \mathrm{pp}$

Mikhail, M.E. and Gracie, G. (1981), "Analysis and Adjustment of Survey measurements”, published by Van Nostrand Reinhold Ltd, New York.

Muskett, J. (2005), “Site Surveying, $2^{\text {nd }}$ edition, Blackwell Science publishers, Oxford, Great Britain

Schofield, W. (2001), Engineering Surveying, $5^{\text {th }}$ edition, published by Butterworth Heinemann, Oxford, Great Britain

Surveyors Council of Nigeria (SURCON) (2003a), "Specifications for Geodetic Surveys in Nigeria, Publication of Surveyors Council of Nigeria (SURCON), Lagos

Surveyors Council of Nigeria (2003b), "Specifications for large Scale, Cadastral and Engineering Surveys in Nigeria", Publication of Surveyors Council of Nigeria (SURCON), Lagos

Uren, J. and Price, W. F. (1994), "Surveying for Engineers", 3rd edition, Published by the Macmillan Press Limited, London, 586pp 